\title{
Airborne multi-axis DOAS measurements of atmospheric trace gases on CARIBIC long-distance flights
}

\author{
B. Dix ${ }^{1, *}$, C. A. M. Brenninkmeijer ${ }^{2}$, U. Frieß ${ }^{1}$, T. Wagner ${ }^{2}$, and U. Platt ${ }^{1}$ \\ ${ }^{1}$ Institute of Environmental Physics, University of Heidelberg, Heidelberg, Germany \\ ${ }^{2}$ Max Planck Institute for Chemistry, Mainz, Germany \\ *now at: Department of Chemistry and Biochemistry, University of Colorado, Boulder, CO, USA
}

Received: 1 December 2008 - Published in Atmos. Meas. Tech. Discuss.: 5 February 2009

Revised: 24 August 2009 - Accepted: 25 September 2009 - Published: 2 November 2009

\begin{abstract}
A DOAS (Differential Optical Absorption Spectroscopy) instrument was implemented and operated onboard a long-distance passenger aircraft within the framework of the CARIBIC project (Civil Aircraft for the Regular Investigation of the atmosphere Based on an Instrument Container). The instrument was designed to keep weight, size and power consumption low and to comply with civil aviation regulations. It records spectra of scattered light from three viewing directions (nadir, $10^{\circ}$ above and below horizon) using a miniaturized telescope system. The telescopes are integrated in the main pylon of the inlet system which is mounted at the belly of the aircraft. Fibre bundles transmit light from the telescopes to spectrograph-detector units inside the DOAS container instrument. The latter is part of the removable CARIBIC instrument container, which is installed monthly on the aircraft for a series of measurement flights.

During 30 flight operations within three years, measurements of $\mathrm{HCHO}, \mathrm{HONO}, \mathrm{NO}_{2}, \mathrm{BrO}, \mathrm{O}_{3}$ and the oxygen dimer $\mathrm{O}_{4}$ were conducted. All of these trace gases except $\mathrm{BrO}$ could be analysed with a $30 \mathrm{~s}$ time resolution. HONO was detected for the first time in a deep convective cloud over central Asia, while $\mathrm{BrO}, \mathrm{NO}_{2}$ and $\mathrm{O}_{3}$ could be observed in tropopause fold regions. Biomass burning signatures over South America could be seen and measurements during ascent and descent provided information on boundary layer trace gas profiles (e.g. $\mathrm{NO}_{2}$ or $\mathrm{HCHO}$ ).
\end{abstract}

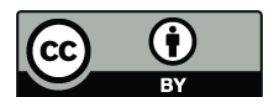

Correspondence to: B. Dix (barbara.dix@colorado.edu)

\section{Introduction}

Earth's atmosphere is a complex and variable system that calls for short-and long-term observations with sufficient spatial and temporal resolution. The CARIBIC aircraft project (Civil Aircraft for the Regular Investigation of the atmosphere Based on an Instrument Container) is a comprehensive approach to obtain detailed long-term observations over large sections of the globe. It represents a successful European enterprise to operate an automated instrument container on board a long-distance passenger aircraft. Presently an Airbus (A340-600) of the German airline Deutsche Lufthansa is being used. The instrument container accommodates 20 in-situ instruments to measure atmospheric constituents like $\mathrm{CO}, \mathrm{O}_{3}, \mathrm{H}_{2} \mathrm{O}, \mathrm{NO}, \mathrm{NO}_{\mathrm{y}}, \mathrm{Hg}$ as well as aerosol number density (Brenninkmeijer et al., 2007). A novel feature of this project (CARIBIC Phase 2) is a DOAS (Differential Optical Absorption Spectroscopy) instrument to measure formaldehyde (HCHO), nitrous acid (HONO), nitrogen dioxide $\left(\mathrm{NO}_{2}\right)$, bromine oxide $(\mathrm{BrO})$ and ozone $\left(\mathrm{O}_{3}\right)$, thus adding a remote sensing capability to CARIBIC. Being a small and light system with very low power consumption, this DOAS setup is particularly well suited for such a project. Measurement flights started in 2005 and will continue until at least 2014.

Unlike previous airborne DOAS measurements (e.g. Wahner et al., 1990; Heue et al., 2005; Bruns et al., 2004, 2006; Wang et al., 2005, 2006), the DOAS system in CARIBIC represents the first long-term and long-distance approach. CARIBIC is helping to fill the gap between ground- and space-based observations: While in-situ measurements and sampling provides detailed information on the

Published by Copernicus Publications on behalf of the European Geosciences Union. 


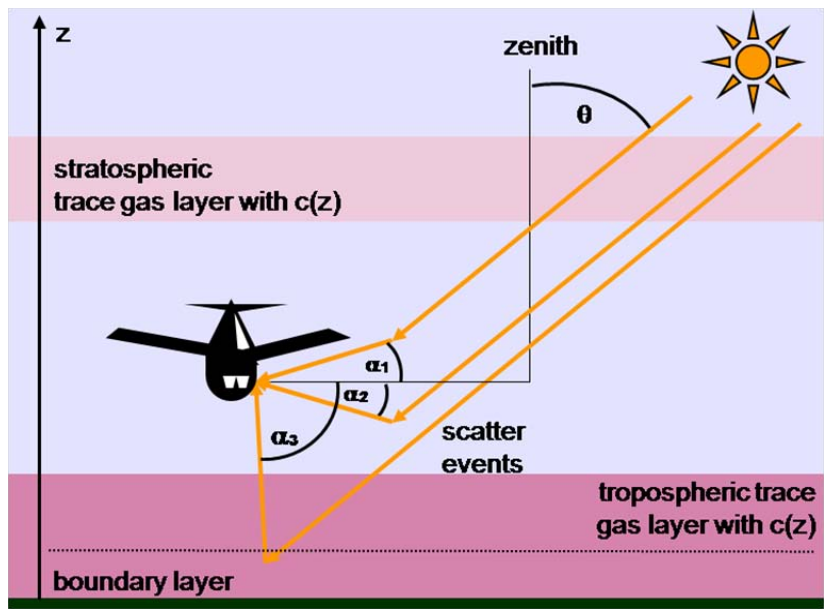

Fig. 1. Observation geometry of the CARIBIC DOAS measurement. Sunlight enters the atmosphere with the solar zenith angle $\Theta$. In a single scattering approximation, the measured photons are scattered once into one of the three detector viewing directions defined by the respective elevation angle $\alpha\left(10^{\circ}\right.$ up, $\alpha_{1}=10^{\circ} ; 10^{\circ}$ down, $\alpha_{2}=-10^{\circ}$; and "nadir", $\alpha_{3}=-98^{\circ}$; since the pylon is mounted at an angle of $8^{\circ}$ from the vertical, the "nadir" viewing telescope looks $8^{\circ}$ from the true nadir direction, but is referred to as nadir direction).

upper troposphere and lower stratosphere (UTLS), the main focus of the CARIBIC DOAS instrument is trace gas measurements in the free troposphere. The specific Multi-Axis DOAS viewing geometry shown in Fig. 1 attains a higher sensitivity towards the free troposphere than most satellite geometries, whereas ground-based instruments are typically most sensitive to the planetary boundary layer. Even though the CARIBIC measurements are confined to the given flight tracks, spatial and temporal resolution are high. The CARIBIC DOAS measurements are in particular motivated by the interest to study the global tropospheric distribution of trace gases such as $\mathrm{BrO}$ (particularly in the mid-latitudes and tropics) or HONO, since many open questions remain regarding the global sources, abundance and sinks of these species (e.g. Lammel and Cape, 1996; Kleffmann et al., 1998; von Glasow et al., 2004; Acker et al., 2006; Saiz-Lopez et al., 2006; Simpson et al., 2007; Volkamer et al., 2007). In addition to measurements at flight altitude, observations during ascent and descent of the aircraft provide information on trace gas concentration profiles in the planetary boundary layer.

After nearly three years of regular measurement flights (with a total of 30 flight operations where DOAS data were collected), a broad spectrum of different findings underlines the significance of the DOAS measurements. For example, HONO has been detected in deep convective clouds for the first time, and on some flights $\mathrm{BrO}, \mathrm{NO}_{2}$ and $\mathrm{O}_{3}$ could be observed in tropopause fold regions, indicating tropospherestratosphere exchange.
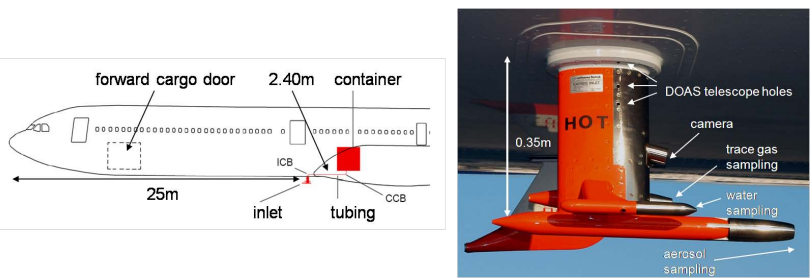

Fig. 2. Left panel: Sketch of the CARIBIC system, showing the position of the inlet system and the instrument container. ICB denotes "Inlet Connector Bracket", CCB stands for "Container Connector Bracket". ICB represents the airtight connection between the inlet sampling tubes and the connecting tubes inside the airplane, while the CCB houses all the necessary fittings for the connection to the container instruments. Adopted from Brenninkmeijer et al., 2007. Right panel: The pylon of the inlet system.

In this study the technical realization and flight performance of the CARIBIC DOAS instrument are presented. First, the MAX-DOAS technique is introduced and a detailed description of the instrumental setup is given. The second part is dedicated to flight performance and data analysis, while the third part presents selected results.

\section{Instrumental setup}

\subsection{Overview}

The CARIBIC system consists of an instrumented container, which is deployed monthly in the forward cargo compartment, and an inlet (see Fig. 2, left panel), permanently mounted on the aircraft fuselage to provide air for the instruments in the container. For the DOAS measurements, a telescope system is integrated in the main pylon of the inlet system (see Fig. 2, right panel). The light is transmitted via quartz fibre bundles to three spectrograph-detector units of identical design inside the DOAS container instrument, where spectra of UV-visible scattered sun light are recorded. When the container is absent, the fibre bundles are stored in the aircraft at the Container Connector Bracket (CCB, see Fig. 2, left panel), and the DOAS windows in the pylon are sealed.

The well established DOAS method (Platt and Perner, 1980; Platt, 1994; Platt and Stutz, 2008) is used to identify trace gases by means of their individual differential (i.e. narrow band) absorption structures. With this method $\mathrm{BrO}$, $\mathrm{NO}_{2}, \mathrm{HONO}, \mathrm{HCHO}, \mathrm{O}_{3}$ and the oxygen dimer $\mathrm{O}_{4}$ were measured during CARIBIC flights. Spectra are recorded between 320 and $460 \mathrm{~nm}$ with a $30 \mathrm{~s}$ time resolution from three different viewing directions, namely $10^{\circ}$ above and below horizon and nadir (see Fig. 1). By applying different telescope elevation angles ( $\alpha$, see Fig. 1$)$, the measurements become sensitive to different atmospheric layers, which is the essence of the Multi-AXis- (MAX-) DOAS approach. Since 


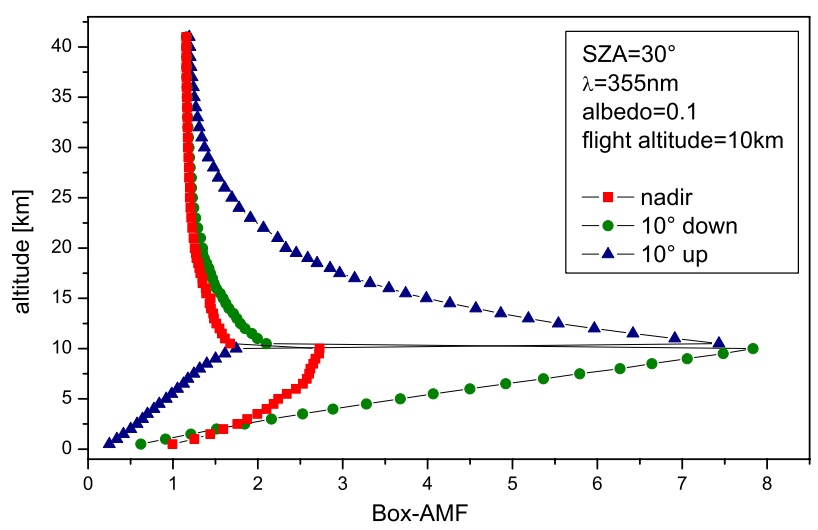

Fig. 3. Box-AirMassFactors (Box-AMFs) for the CARIBIC DOAS viewing geometries (nadir, $10^{\circ}$ down, $10^{\circ}$ up), calculated at a wavelength of $355 \mathrm{~nm}$ for a typical cruising height and Solar Zenith Angle (SZA), which are suitable for most trace gases observed during the experiments.

MAX-DOAS utilises scattered sun light as a light source, there is no well defined single light path (although in many cases the general dependencies of MAX-DOAS observations can be well described by a single scattering approximation, see Fig. 1). Therefore the result of the DOAS analysis is a Slant Column Density (SCD), which is the weighted average over the integrated concentrations along all possible light paths (e.g. Solomon et al., 1987; Perliski and Solomon, 1993; Marquard et al., 2000).

The sensitivity of this type of viewing geometry can be expressed by Box-AirMassFactors (Box-AMFs), as shown in Fig. 3. These Box-AMFs are calculated with Tracy II (Deutschmann and Wagner, 2006; Wagner et al., 2007), a backward Monte Carlo radiative transfer model. They quantify the contribution of a thin layer of trace gas to the SCD and thus the DOAS signal. Box-AMFs are calculated for a typical cruising altitude and Solar Zenith Angle (SZA) at a wavelength of $355 \mathrm{~nm}$, which is representative for most trace gases observed during the experiments. Each Box-AMF denotes how sensitive the measurements are towards changes of the vertical trace gas column within a given box, i.e. an atmospheric layer of height $h$. It is apparent that the slant viewing directions yield the highest sensitivities to atmospheric layers directly above and below the aircraft. The nadir direction exhibits overall smaller Box-AMFs, yet it provides the highest sensitivity towards layers near the surface.

Overall, the CARIBIC DOAS instrument is designed to keep weight and power consumption low. The equipment is reduced to essential parts and miniaturized where possible. The telescope system could be realized by three miniaturized telescope units, housed in a small aluminium block (see Fig. 4). The DOAS container instrument fits in one of five 19" racks of the CARIBIC instrument container, weighs $16 \mathrm{~kg}$ and needs $75 \mathrm{~W}$ at maximum cool-
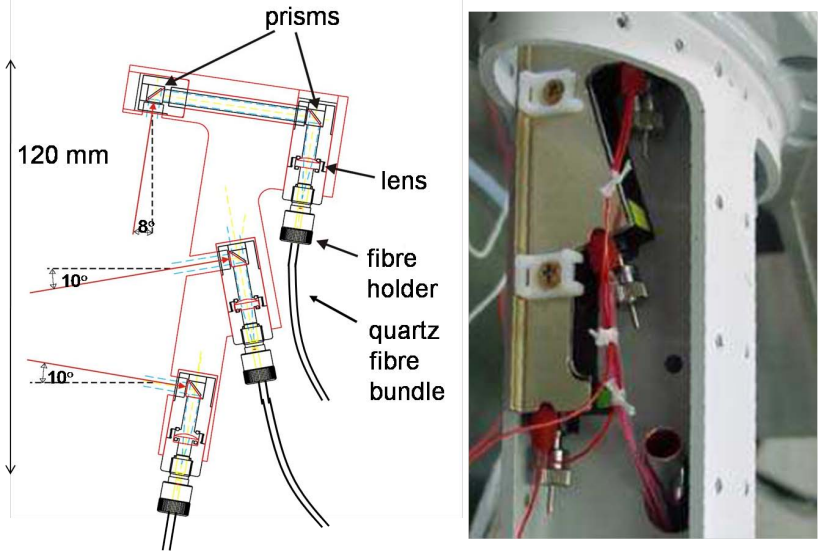

Fig. 4. Left panel: Sketch of the telescope block. The viewing directions (nadir, $10^{\circ}$ down, $10^{\circ}$ up) are indicated by red lines, dashed lines indicate horizontal and vertical directions, respectively. Note that the "nadir" telescope actually looks $8^{\circ}$ to the right (as seen looking in flight direction) caused by a slightly tilted mounting of the inlet. Total length of the telescope block is $120 \mathrm{~mm}$. Right panel: The telescope block in the inlet during assembly. The Ultra Torr Adapters for the connection of the quartz fibre bundles (here shown plugged) as well as the red cables of the heating pads are visible.

ing power. It houses three temperature stabilized custom made spectrograph-detector units based on Ocean Optics USB2000 miniature spectrometers, power supplied via USB by an embedded PC (see Sect. 2.4 below).

Apart from restricted weight and power consumption, all components must be able to sustain vibrations and the inlet system needs to endure daily strong temperature differences over years. Moreover, using a passenger aircraft for regular measurements requires that all instrumentation needs to be built in compliance with civil aviation regulations, which in summary leads to the following requirements: (1) All instruments need to pass an electromagnetic compatibility test. (2) Measurements must be fully automated and controlled by a master computer. (3) All parts permanently installed in the aircraft should be maintenance free.

\subsection{The telescope system in the pylon}

As stated above, the telescope system consists of three miniaturized telescope units, mounted in a $120 \times 70 \times 15 \mathrm{~mm}$ aluminium block (Fig. 4). Each telescope unit serves as entrance optics for its respective viewing direction. The pylon is mounted at the lower side of the aircraft body at an angle of $8^{\circ}$ to the right (looking in flight direction) from the vertical. Therefore the "nadir" viewing telescope looks $8^{\circ}$ from the true nadir direction, but is referred to as nadir direction. Each telescope unit consists of a quartz lens, one or two quartz prisms and a filter (Schott UG5). The filter reduces the intensity of radiation with wavelengths above $400 \mathrm{~nm}$ 
to reduce stray light in the desired wavelength range (320$400 \mathrm{~nm}$ ). Incoming light is reflected by $90^{\circ}$, using prisms $(5 \times 5 \mathrm{~mm})$, and then focused on the entrance of quartz fibre bundles by lenses $(f=15 \mathrm{~mm})$. The units are air tight to prevent condensation of water vapour on optical components. During measurement flights, the telescope block is heated ( $15 \mathrm{~W}$, unregulated) to avoid freezing of water on the outside surface of the entrance optics (prisms). The field of view of each telescope is $1.9^{\circ}$ (full angle). For a typical flight altitude of $10 \mathrm{~km}$, an aircraft velocity of $900 \mathrm{~km} / \mathrm{h}$, and a time resolution of $30 \mathrm{~s}$, the ground pixel covered by the nadir field of view is $0.33 \mathrm{~km}$ (cross track) by $7.8 \mathrm{~km}$ (along track).

The quartz fibre bundles are connected to the telescopes by $1 / 16$ " Swagelok Ultra Torr adapters. These are air tight and the nuts are secured with an adhesive that endures large temperature variations. The sealing o-ring of each adapter was replaced by a silicone ring compatible with temperatures down to $-60^{\circ} \mathrm{C}$. Before each measurement flight the telescope entrance prisms are inspected and cleaned if necessary. After the flight the telescope entrance holes are covered with metal tape to keep out dirt. Otherwise the telescope system is maintenance free.

\subsection{The quartz fibre bundles}

The telescopes are connected to the spectrometers by three $5 \mathrm{~m}$ long quartz fibre bundles, each consisting of 4 individual quartz fibres with a diameter of $210 \mu \mathrm{m}$ and a numerical aperture of $0.22(f / 2)$. At the telescope end, the four fibres are arranged in a rectangular geometry to fit the area illuminated by the quartz lens. At the spectrometer end (exit) the fibre bundles are arranged in a column, in order to optimize the illumination of the $50 \mu \mathrm{m}$ wide and $1000 \mu \mathrm{m}$ high spectrometer entrance slit. A quartz fibre bundle has a greater tolerance to bending, compared to a single, thicker fibre, which was necessary as the integration of the fibre bundles in the inlet system required a bending radius of as low as $60 \mathrm{~mm}$. Also, fibre bundles are known for largely reducing the polarization sensitivity of grating spectrometers (Stutz and Platt, 1997).

Figure 4 (right panel) shows a photograph of the DOAS telescope block, taken during the assembly of the inlet system. The whole procedure of installing the inlet system with the DOAS block was a rather complex procedure. The entire inlet system had been fully pre-assembled prior to aircraft mounting. Since the instrument connectors of the three quartz fibre bundles were too bulky to fit through the inlet system, the respective telescope ends were fed from the aircraft above through the inlet via a metal tube upon aircraft installation. This tube served as a guide during the installation, and prevents damage to the fibre bundles in use. After this the optical connection with the Ultra Torr adaptors was made, and the inlet system was slowly raised until contact with the fuselage. Finally the three fibre bundles were sealed with aviation type potting mix inside $\mathrm{a} 1 / 2 \mathrm{inch}$ piece of stainless steel tubing that was held by a bulk union (Swagelok) mounted in the so called "pressure box", i.e. the pressure seal feedthrough inside the aircraft (Inlet Connector Bracket, ICB, see Fig. 2, left panel). The quartz fibre bundles run underneath the cargo compartment floor panels from the ICB to the CCB. The CCB is a $30 \mathrm{~cm}$ square, $15 \mathrm{~cm}$ deep trough in the floor, containing all inlet tubing. The fibre bundles are stored in a drum inside the CCB and are carefully uncoiled and connected to the DOAS instrument upon installing the container in the aircraft. Straps support the fibre bundles from the CCB to the instrument $1.20 \mathrm{~m}$ above the CCB.

\subsection{The DOAS container instrument}

Figure 5 provides a block diagram of the container component of the DOAS instrument. Apart from the spectrographdetector units, cooling and computer, the instrument consists of the following components: an RS232 - Ethernet converter to establish communication to the master computer in the container, an EMC-filter and a DC/DC converter (VICOR). The instrument housing (ratiopac PRO) is designed to reduce electromagnetic interference. This setup proved to be sufficient to pass the necessary electro-magnetic radiation test.

The "heart" of the container instrument is three Ocean Optics USB2000 spectrograph-detector units $(90 \times 60 \times 35 \mathrm{~mm})$, one for each viewing direction. The spectrograph $(F / \#=4)$ is a crossed Czerny-Turner type, which reduces the required optical bench size. The spectrometers use plane diffraction gratings (Ocean Optics grating \#7, $2400 \mathrm{gr} / \mathrm{mm}$, holographic). The detector itself consists of a linear CCD array with 2048 pixels (SONY ILX511) and the whole system provides a spectral resolution of $0.7 \mathrm{~nm}$ (FWHM). The three spectrometers are mounted in a separate air tight box to prevent condensation of water vapour and to increase temperature stability, since changes in the optical adjustment affect the spectral retrieval. Accordingly, the connections of the quartz fibre bundles to the spectrograph-detector units need to be airtight. For this purpose 1/4" cylindrical stainless steel end pieces were glued to each quartz fibre bundle. The cylindrical end pieces are the counterpart of 1/4" Swagelok Ultra Torr Adapters. In order to ensure the correct optical alignment of the quartz fibre bundle exit and the entrance slit of the spectrographs, the fibre bundle end pieces and the Ultra Torr adapters are equipped with spanner flats, allowing only a connection in the correct position. The temperature control unit uses a PT100 sensor for measuring the optical bench temperature, an electronic temperature controller, and three Peltier elements inside the spectrograph box for cooling. The temperature was usually set to $+18^{\circ} \mathrm{C}$, compromising between reducing the dark current and occasional high ambient temperatures (exceeding $+40^{\circ} \mathrm{C}$ ).

The spectrograph-detector units are conveniently connected and supplied with power via USB ports of the measurement computer $(96 \times 116 \mathrm{~mm}, \mathrm{PC} / 104,200 \mathrm{MHz}$ processor type Geode GX1, $10 \mathrm{~W}$ ). An active USB hub is employed 


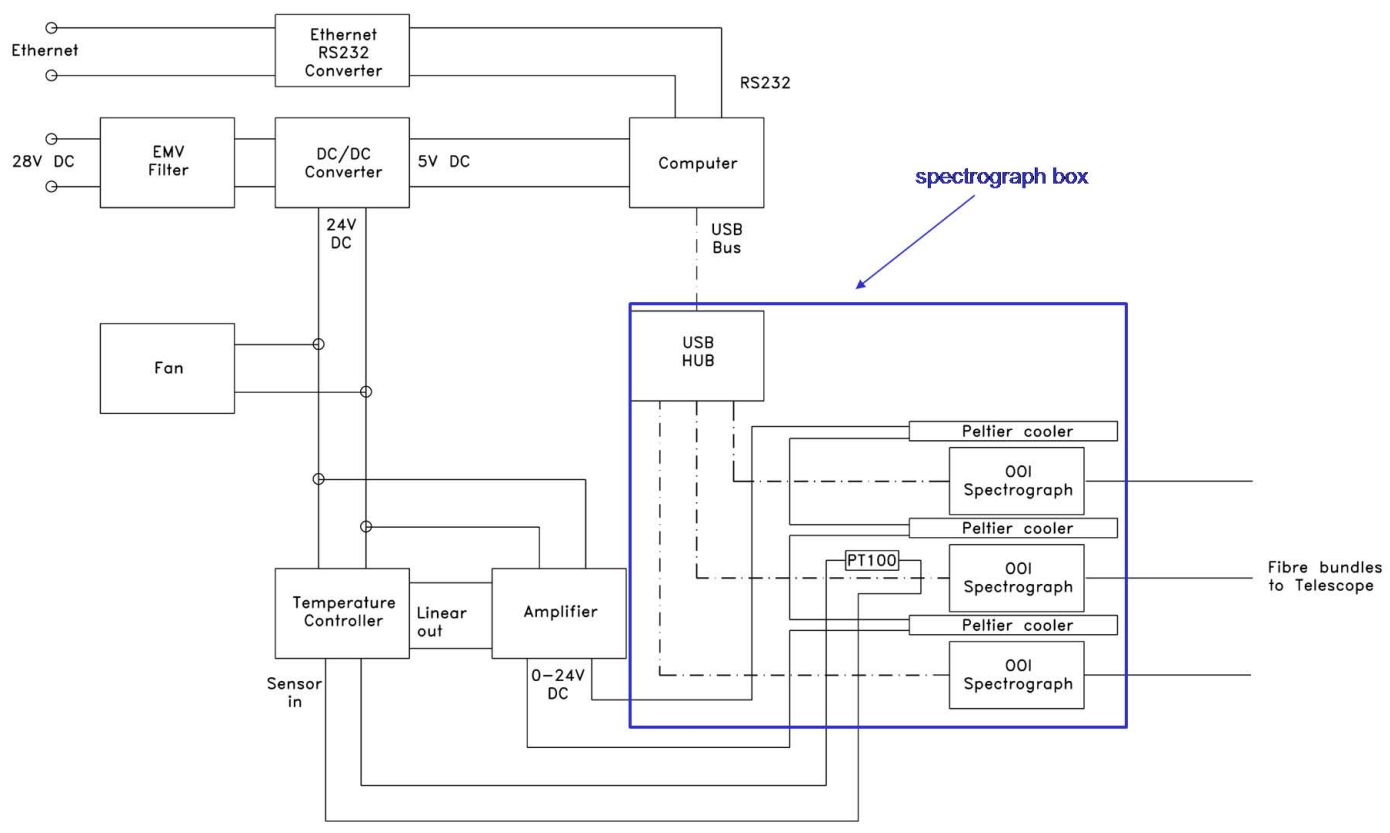

Fig. 5. Block diagram of the electrical connections within the DOAS container instrument.

to provide the necessary number of USB connections. A 1 GB flash memory card serves as hard drive and is used for data storage. The measurement program is based on Windows 2000. The remaining data storage space on the memory card corresponds to about $45 \mathrm{~h}$ of measurements. A set of monthly measurement flights (e.g. return flight to Santiago de Chile via São Paulo, Brazil) provides typically about $30 \mathrm{~h}$ of data, using a $30 \mathrm{~s}$ exposure time per spectrum. To attain a better signal-to-noise ratio, 5,10 or 15 consecutive spectra were co-added after flight, resulting in time resolutions of 150,300 , or 450 seconds, corresponding to $39 \mathrm{~km}$ to $117 \mathrm{~km}$ of spatial resolution (along track).

The measurement software controls the fully automated measurements and starts once power is provided. It records scattered light spectra during daytime and background spectra during night. It also establishes communication with the Master PC as required. Thereby, e.g. the PC time is synchronized. Since the DOAS instrument needs only little power, it is allowed to measure during ascent and descent, while larger power consumers in the container need to be switched off due to safety requirements.

\section{Flight performance and data analysis}

A total of 30 monthly flight operations from Frankfurt/Main were performed with the CARIBIC MAX-DOAS system up to February 2008. Flight destinations were South America (Santiago de Chile via São Paulo, Brazil) and South-East Asia (Manila via Guangzhou, China). Also destinations in the US and India were visited. Some $40-60 \%$ of the flight time, depending on the season, was spent during daytime on these routes in 2005-2007. Since all respective flight legs over oceans and in the tropics took place at night time, DOAS data was collected over continents in mid-latitudes and the subtropics.

The deployed DOAS hardware proved to be suitable and reliable on these flights. However, during the course of measurement flights in 2005 , the $10^{\circ}$ up and $10^{\circ}$ down viewing directions exhibited very low light intensities compared to the results of the very first measurement flight. This issue will be addressed separately in Sect. 3.1. The measurement software was updated several times to attain a higher stability and to include automated background measurements and a watchdog program. Occasionally, temperature instabilities caused by strong changes in the ambient (container) temperature, in particular during landing and take-offs, led to shifts in the wavelength calibration of the spectrometer. However, this could mostly be corrected during the data analysis procedure. The overall flight performance proved regular DOAS measurements on long-distance flights to be very well feasible.

\subsection{Performance of the DOAS telescopes and fibre bundles}

During 2005 the light sensitivity of the $10^{\circ}$ up and $10^{\circ}$ down viewing telescopes decreased and continued to be very low, sometimes even zero, so that unfortunately until February 2008 data was mainly available from the nadir viewing direction only. Since tests showed that the container instrument could be excluded as an error source, the problem could 
Table 1. Trace gas references.

\begin{tabular}{lll}
\hline No. & Molecule & Reference \\
\hline 1 & $\mathrm{NO}_{2}(220 \mathrm{~K})$ & Vandaele et al., 1997 \\
2 & $\mathrm{NO}_{2}(294 \mathrm{~K})$ & Vandaele et al., 1997 \\
3 & $\mathrm{O}_{4}(298 \mathrm{~K})$ & Hermans, 2002 \\
4 & $\mathrm{BrO}(228 \mathrm{~K})$ & Wilmouth et al., 1999 \\
5 & $\mathrm{HCHO}(298 \mathrm{~K})$ & Meller and Moortgat, 2000 \\
6 & $\mathrm{HONO}(294 \mathrm{~K})$ & Stutz et al., 2000 \\
7 & $\mathrm{O}_{3}(223 \mathrm{~K})$ & Bogumil et al., 2003 \\
8 & $\mathrm{O}_{3}(243 \mathrm{~K})$ & Bogumil et al., 2003 \\
\hline
\end{tabular}

only be addressed upon detachment of the inlet system. In January 2008, the inlet system had to be taken off as part of a major routine aircraft check. On this occasion the quartz fibre bundles and the telescope system were replaced. It turned out that the connection of the quartz fibre bundles to the telescope had become loose for the $10^{\circ}$ up viewing direction and that the UG5 filter in the $10^{\circ}$ down viewing telescope unit had been broken to pieces, either due to temperature stress or vibrations or both. After the replacement the light intensity of all three viewing directions is satisfying. The telescope system was replaced without modifications, whereas the quartz fibre bundles were replaced by new ones: They now consist of 6 individual quartz fibres of $150 \mu \mathrm{m}$ each and with a numerical aperture of $0.11(f / 4)$ to better adjust to the specifications of the spectrograph-detector units. To prevent any quartz fibre bundles from becoming loose again, the U1tra Torr Adapters are now additionally secured with a silicone sealant applied to the outside of the connector.

As noted above, upon each measurement flight, the quartz fibre bundles are connected to the respective spectrographdetector unit in the DOAS container instrument. This procedure implies a lot of handling, thus exposing the quartz fibre bundles to a higher risk of breaking. However, until their renewal in January 2008 the bundles proved to be sufficiently robust: Merely two (one out of four individual fibres in two bundles) were broken during almost three years of flight time with a total of 30 install - uninstall cycles. It is fair to assume that the new cables will last for years.

\subsection{Data analysis and detection limit}

The WinDOAS software (Fayt and van Roozendael, 2001) was used for the DOAS data analysis. It performs a nonlinear least squares fit by simultaneously adjusting the relevant atmospheric absorbers in the respective wavelength range to the measured spectra. To account for broad band effects (in particular caused by Rayleigh- and Mie-scattering) a polynomial of degree $2-5$ is included. The fitting procedure is performed with the logarithm of the spectra (i.e. in optical density rather than intensity space). Before the logarithm is taken a linear intensity offset was included in each fitting process to account for instrumental stray light. The absorption cross section references used for data analysis are listed in Table 1. Each flight was evaluated with a Fraunhofer reference spectrum consisting of 10 or 15 co-added spectra from the same flight to account for Fraunhofer absorption lines. Therefore measured slant column densities are differential Slant Column Densities (dSCDs). To account for the "filling in" of Fraunhofer lines due to rotational Raman scattering ("Ring effect", Grainger and Ring 1962), a Ring reference spectrum was calculated from the respective Fraunhofer reference with the DOASIS software (Kraus, 2006). The analysis settings for each trace gas are summarised in Table 2 . References in parentheses indicate that the particular trace gas reference was only fitted where applicable, e.g. during ascent and descent.

For the current instrumental setup, a realistic detection limit is estimated by twice the statistical error resulting from the fitting procedure (standard deviation $\sigma$ of the optical density of the fit residual) (Stutz and Platt, 1996). This detection limit is valid for mostly unstructured residuals. Sensitivity studies have shown that some residuals contain systematic structures. However, for stable instrument conditions, high light intensities and a reference spectrum close in time to the analysed spectrum $(<30 \mathrm{~min})$, the fit residuals were mostly unstructured. In this case $\sigma$ was found to be $5 \cdot 10^{-4}$ for a time resolution of $30 \mathrm{~s}$ and $\sigma=3.2 \cdot 10^{-4}$ for a time resolution of $7.5 \mathrm{~min}$ ( 15 co-added spectra). The observed reduction is not as much as expected for purely statistical errors, indicating that some systematic deviations in the residuals remain. Resulting detection limits are given in Table 2 expressed as $\mathrm{dSCD}_{\text {limit }}$ for all trace gases. These limits appear to be realistic, since the scatter of the dSCD data is of the same order of magnitude. Shorter detector exposure times lead to higher photon noise, therefore, a 30 s integration time (and thus time resolution) can be regarded as rather good for scattered-light DOAS measurements, particularly when using a small Ocean Optics USB2000 spectrometer. It is therefore quite a success that many trace gases could be analysed above the detection limit even within the $30 \mathrm{~s}$ time resolution.

Examples for the spectral retrieval of $\mathrm{NO}_{2}, \mathrm{HCHO}$ and HONO are shown in Figs. 6 and 7. Reference spectra were always taken from clean regions, which were determined by choosing periods of minima in DOAS $\mathrm{NO}_{2}$ and $\mathrm{HCHO}$ data and in in-situ measured $\mathrm{NO} / \mathrm{NO}_{\mathrm{y}}$ and $\mathrm{CO}$. The analysis was performed using spectra with a $30 \mathrm{~s}$ time resolution taken from the nadir viewing direction, which applies to all results thereafter, except where stated otherwise. $\mathrm{NO}_{2}$ and $\mathrm{HCHO}$ are measured during ascent in the polluted boundary layer of Guangzhou, China, while HONO was detected for the first time inside a deep convective cloud over central China (see Sect. 4). The evaluation of HONO was checked particularly careful in this case to make sure that the observed absorption structure is real. (Observed deviations for different analysis settings were within 10\%). 
Table 2. Analysis settings and detection limits

\begin{tabular}{llllll}
\hline trace gas & $\begin{array}{l}\text { wavelength } \\
\text { range [nm] }\end{array}$ & fitted absorber & $\begin{array}{l}\text { polynomial } \\
\text { order }\end{array}$ & $\begin{array}{l}\text { detection limit } \\
\text { dSCD (30 s) } \\
{\left[\mathrm{molec} / \mathrm{cm}^{2}\right]}\end{array}$ & $\begin{array}{l}\text { detection limit } \\
\text { dSCD (7.5 min }) \\
{\left[\mathrm{molec} / \mathrm{cm}^{2}\right]}\end{array}$ \\
\hline $\mathrm{NO}_{2}$ & $354-380$ & $1,(2), 3,7,8$ & 3 & $6.5 \times 10^{15}$ & $4.2 \times 10^{15}$ \\
$\mathrm{O}_{4}$ & $350-356$ & $1,(2), 3,7,8$ & 2 & $2.5 \times 10^{42}$ & $1.6 \times 10^{42}$ \\
$\mathrm{BrO}$ & $345-360$ & $1,3,4,7,8$ & 2 & $1.3 \times 10^{14}$ & $8.0 \times 10^{13}$ \\
$\mathrm{HCHO}$ & $328-359$ & $1,(2), 3,4,5,(6), 7,8$ & 4 & $1.8 \times 10^{16}$ & $1.2 \times 10^{16}$ \\
$\mathrm{HONO}$ & $337-375$ & $1,(2), 3,4,5,6,7,8$ & 4 & $2.5 \times 10^{15}$ & $1.6 \times 10^{15}$ \\
$\mathrm{O}_{3}$ & $329.5-343$ & $1,3,7,8$ & 2 & $2.5 \times 10^{18}$ & $1.6 \times 10^{18}$ \\
\hline
\end{tabular}
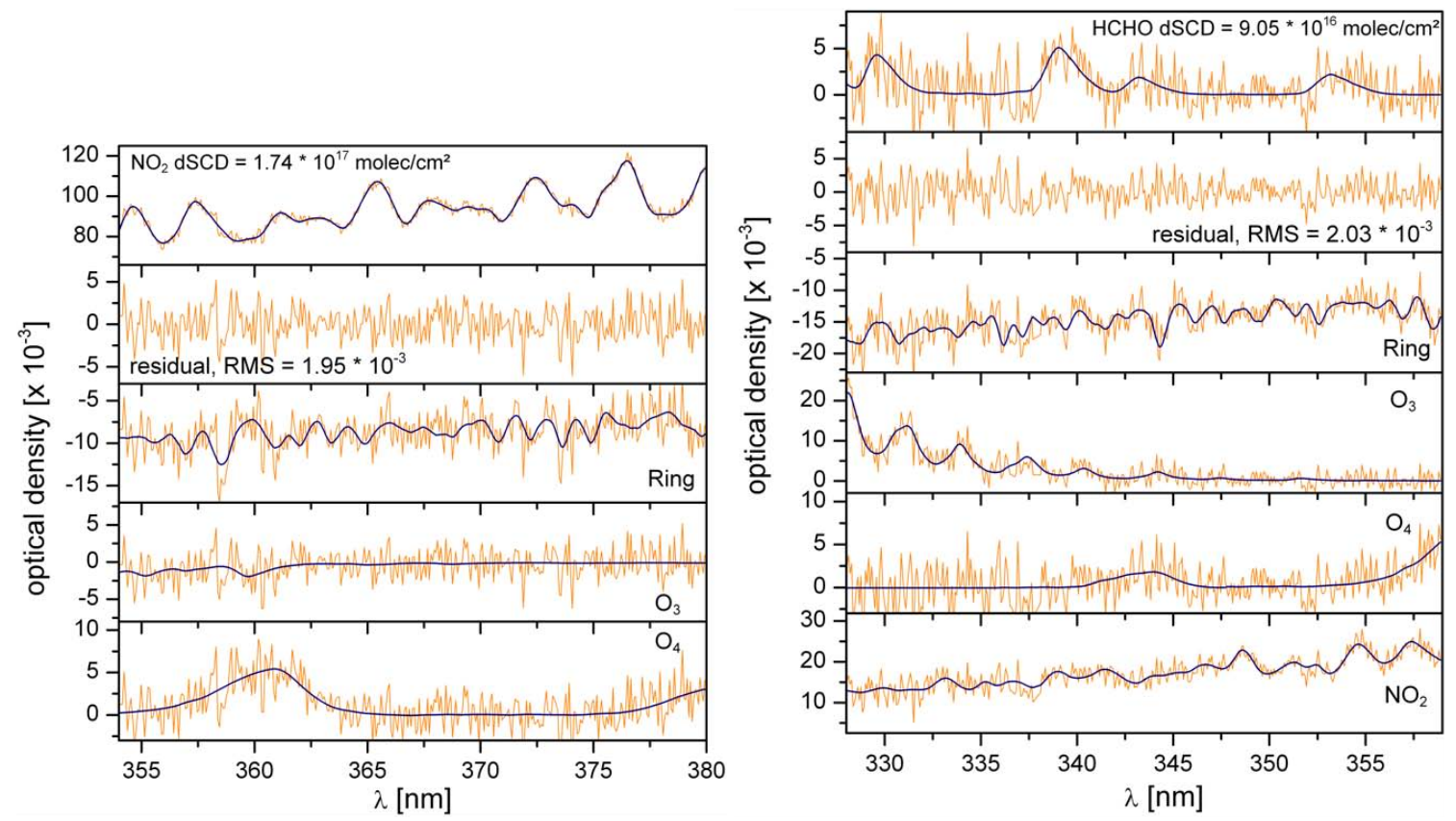

Fig. 6. Example for the spectral retrieval of $\mathrm{NO}_{2}$ (left panel) and $\mathrm{HCHO}$ (right panel) (both nadir). The black lines represent the fit results for the different trace gas cross sections; the orange lines show the residual structure added to the retrieved absorption structure. The analysis is performed on spectra recorded within the boundary layer upon landing in Guangzhou, China on 1 August 2006. The spectrum for the $\mathrm{NO}_{2}$ analysis is recorded at an altitude of $1.3 \mathrm{~km}$ with a SZA of $34^{\circ}$, that for $\mathrm{HCHO}$ at $1.7 \mathrm{~km}$ and SZA $=33.8^{\circ}$ respectively. The reference spectrum is taken from the same flight over a clean region at an altitude of $11.4 \mathrm{~km}$ with a SZA of $17.6^{\circ}$.

\section{Exemplary results}

The dSCD time series measured inside the aforementioned deep convective cloud on 1 August 2006 over central China $\left(106.5^{\circ} \mathrm{E}, 27.1^{\circ} \mathrm{N}\right.$, flight altitude $\left.=11.4 \mathrm{~km}\right)$ is shown in Fig. 8. Shortly after 05:55 UTC a peak in all slant columns can be seen, except for BrO. The red box indicates the time period of the aircraft flying inside the cloud. Video recordings of the forward looking camera mounted in the pylon reveal that the aircraft travelled completely inside a large cloud during this period. This is further confirmed by coincident high in-situ total water values (A. Zahn, personal communication, 2007, CARIBIC database). In this case the measured
dSCDs are very likely enhanced by multiple scattering inside the cloud as suggested by the peak in $\mathrm{O}_{4}$ column values.

The deep convective cloud is characterized by the presence of elevated columns of $\mathrm{HONO}, \mathrm{NO}_{2}, \mathrm{HCHO}$ and $\mathrm{O}_{3}$. Simultaneously in-situ measured $\mathrm{NO}$ and $\mathrm{NO}_{\mathrm{y}}$ peak (H. Ziereis, personal communication, 2007, CARIBIC database), whereas $\mathrm{O}_{3}$ and $\mathrm{CO}$ mixing ratios drop sharply (A. Zahn, F. Slemr, D. Scharffe, personal communication, 2007, CARIBIC database), indicating the presence of a distinct air mass that had not yet been mixed with ambient air. Generally, $\mathrm{O}_{3}$ dSCDs measured in the nadir viewing direction are dominated by the stratospheric ozone signal and are 


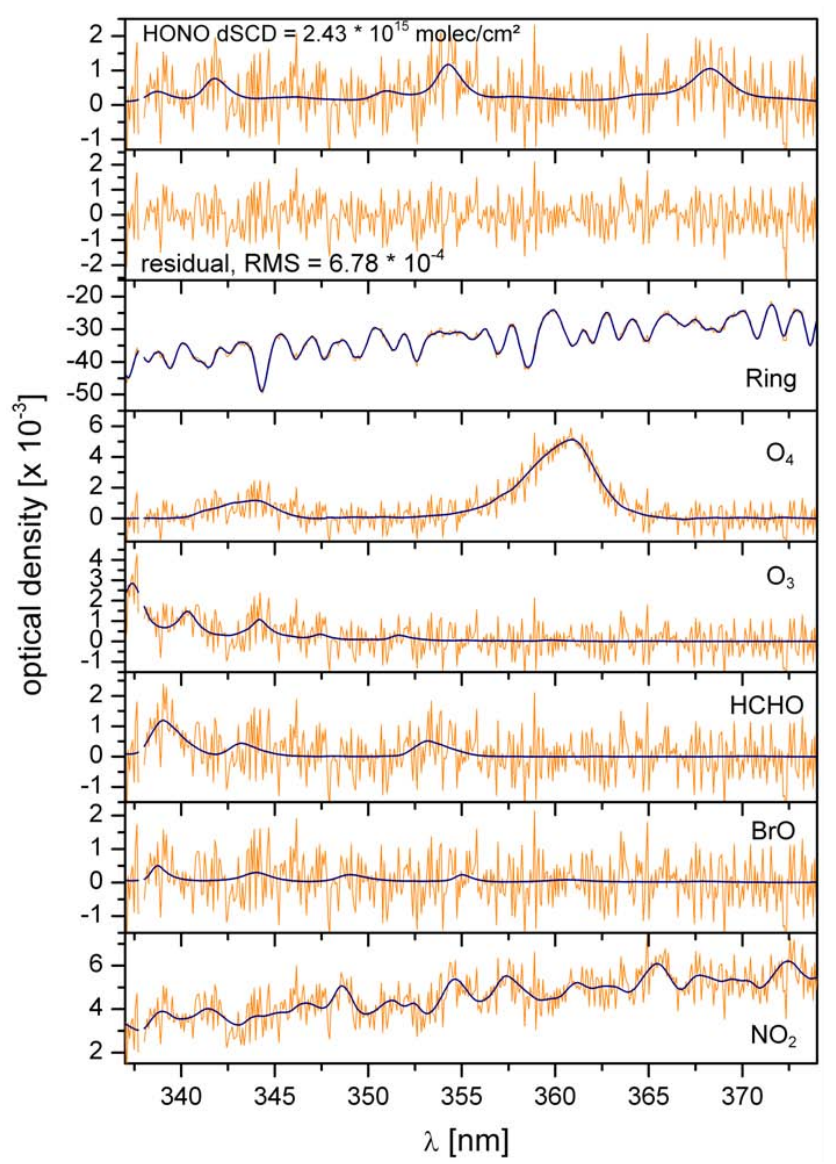

Fig. 7. Example of a spectral retrieval of HONO (nadir). The black lines represent the fit results for the different trace gas cross sections; the orange lines show the residual structure added to the retrieved absorption structure The analysis is performed on a spectrum recorded inside a deep convective cloud on 1 August 2006 over central China $\left(106.5^{\circ} \mathrm{E}, 27.1^{\circ} \mathrm{N}\right)$ at an altitude of $11.4 \mathrm{~km}$ with a SZA of $15.6^{\circ}$. The reference spectrum is taken over a clean region from the same flight and altitude with a SZA of $17.6^{\circ}$ (see also Fig. 8).

hardly sensitive to tropospheric $\mathrm{O}_{3}$ unless there are extensive light path enhancements. In-situ measured $\mathrm{O}_{3}$ is in the same order of magnitude inside the cloud as where the reference spectrum is taken (at 05:40 UTC) and the corresponding change of the stratospheric contribution is negligible. It is therefore assumed that the peak in the $\mathrm{O}_{3}$ dSCDs is mainly caused by multiple scattering effects inside the cloud. Insitu NO, in contrast, is below detection limit at 05:40 UTC (H. Ziereis, personal communication, 2007, CARIBIC data base) and peaks inside the cloud, giving reason to assume that the $\mathrm{NO}_{2}$ and $\mathrm{HONO}$ dSCD peaks and possibly also the $\mathrm{HCHO}$ peak are caused by an increased concentration in this specific air mass.

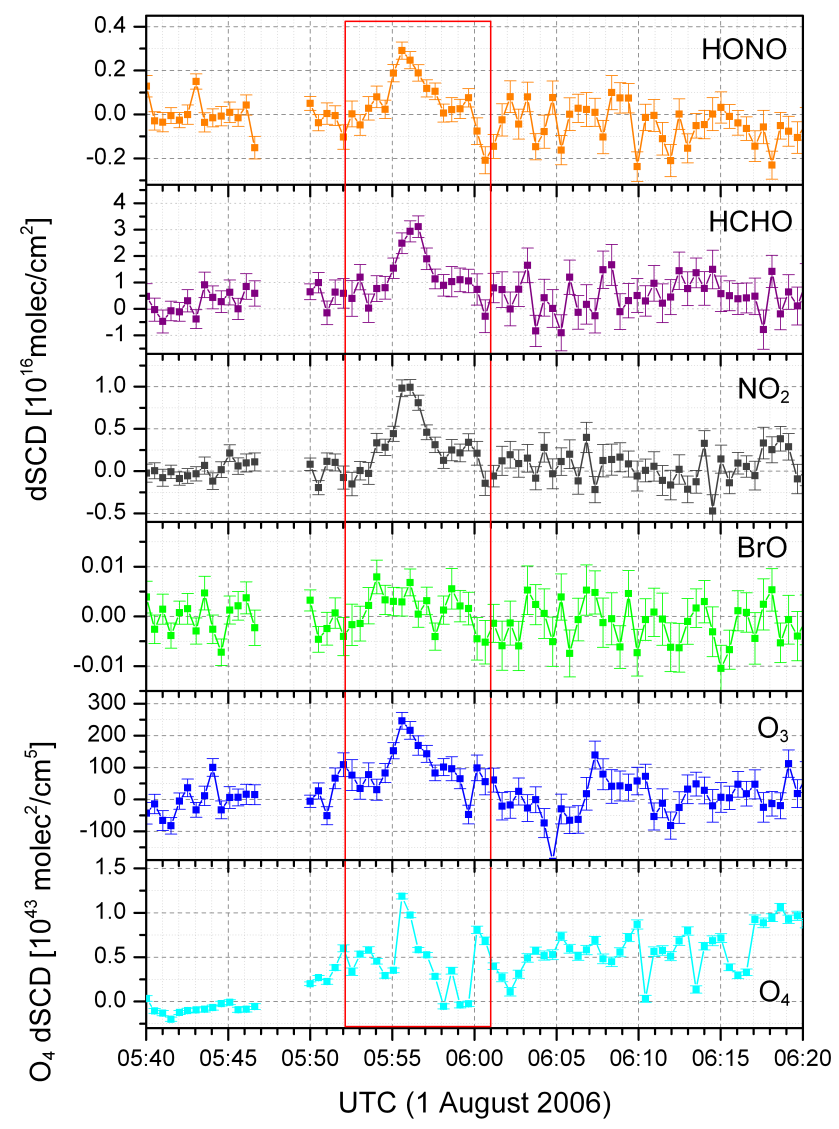

Fig. 8. DOAS results of measurements inside a deep convective cloud over central China on 1 August $2006\left(106.5^{\circ} \mathrm{E}, 27.1^{\circ} \mathrm{N}\right)$ at an altitude of $11.4 \mathrm{~km}$ with a SZA of $15.6^{\circ}$. The reference spectrum is taken from the same flight and altitude with a SZA of $17.6^{\circ}$ over a clean region at 05:40 UTC. The time period of cloud interception is indicated by a red box. Inside the cloud, all trace gases show enhanced slant columns, except BrO.

Data of the World Wide Lightning Location Network (see http://webflash.ess.washington.edu) shows lightning activity in this area for the same period of time. It is thus likely that the observed $\mathrm{NO}_{2}$ and $\mathrm{HONO}$ were formed in-situ, HONO by lightning induced $\mathrm{OH}$ and $\mathrm{NO}$, while elevated $\mathrm{HCHO}$ levels could be explained by either direct formation and/or reaction of $\mathrm{OH}$ with methane or by the concomitant updraft of polluted air through deep convection (e.g. Bhetanabhotla et al., 1985). Since HONO photolyzes quickly, it is highly unlikely that it had been transported to this height from a ground based pollution source.

Converting the HONO peak dSCD into a mixing ratio yields about $70 \mathrm{ppt} \mathrm{HONO}$. This conversion was done in two steps: 1) In order to derive a proper AMF for the measurement inside the cloud, the above introduced radiative transfer model Tracy II was used to vary modelled cloud properties, until measured and modelled $\mathrm{O}_{4}$ SCDs agreed. The single scattering albedo was set to 0.99999 and the asymmetry 
parameter $\mathrm{g}$ to 0.85 , which are suitable values for most cloud scenarios. Initial cloud top heights $(12-18 \mathrm{~km})$ as well as cloud optical density (60) were taken from MODIS data (http://ladsweb.nascom.nasa.gov). The best agreement of $\mathrm{O}_{4}$ SCDs (within 5\%) was achieved for a cloud with an optical density of 100 , expanding from $2 \mathrm{~km}$ up to $14-15 \mathrm{~km}$ altitude, which are suitable values for a deep convective cloud near the Tropics. 2) Utilizing these best fitting cloud properties resulted in an AMF of about 8 for light path enhancements within the cloud.

Subsequently the above stated HONO mixing ratio was calculated, assuming a homogeneous trace gas distribution inside the cloud. To get a first estimate on the quality of this conversion, the peak $\mathrm{O}_{3}$ dSCD was also converted into a mixing ratio, yielding about $55 \mathrm{ppb}$, compared to 60 to $65 \mathrm{ppb}$ measured in-situ (A. Zahn, personal communication, 2007, CARIBIC data base), which is within $15 \%$ and renders this method a reasonable approach.

Time series of the same trace gases during the traverse of a biomass burning plume are presented in Fig. 9. These data were recorded during a return flight between São Paulo and Santiago de Chile on 5 October 2005. Biomass burning signatures are marked with a red box. Enhanced slant columns of $\mathrm{NO}_{2}$ and $\mathrm{HCHO}$ measured by DOAS coincide with high $\mathrm{NO}_{\mathrm{y}}(\mathrm{H}$. Ziereis, personal communication, 2007, CARIBIC database) and CO (F. Slemr, D. Scharffe, personal communication, 2007, CARIBIC database) mixing ratios observed by in-situ instruments. Combining these findings with trajectory studies, $\mathrm{CO}-\mathrm{O}_{3}$ correlations and aerosol measurement results can yield information on origin and age of the air mass(es). Furthermore, the flight track crossed massive clouds (information taken from ECMWF data, see http://www.knmi.nl/samenw/campaign support/CARIBIC), coinciding with lightning activity (information taken from NASA's lightning imaging sensor (LIS, see http://thunder.msfc.nasa.gov) and a peak in the HONO slant column density. This is perhaps a similar finding to that over China, while the contribution of biomass burning $\mathrm{NO}_{\mathrm{x}}$ to the HONO formation is unclear.

Periods when the aircraft was flying in lower stratospheric air (in or just above the tropopause) are indicated by green boxes in Fig. 9. Higher slant columns of $\mathrm{O}_{3}$ can be clearly identified and the effect is also slightly visible in the $\mathrm{NO}_{2}$ columns, as both trace gases exhibit maxima in the stratosphere. The "down welling" of the tropopause is caused by tropopause folding activity over the Andes, which is a common phenomenon in this region. Both, $\mathrm{O}_{3}$ and $\mathrm{NO}_{2}$ dSCDs are also affected by stratospheric light path enhancements caused by a change in SZA. The trace of the local SZA (Fig. 9) indicates this effect on measured slant columns, which is again clearly visible in the $\mathrm{O}_{3}$ columns and less pronounced in the $\mathrm{NO}_{2}$ columns. Superimposed features as seen in the red and green boxes for $\mathrm{O}_{3}$ and $\mathrm{NO}_{2}$ are consequently due to other causes.

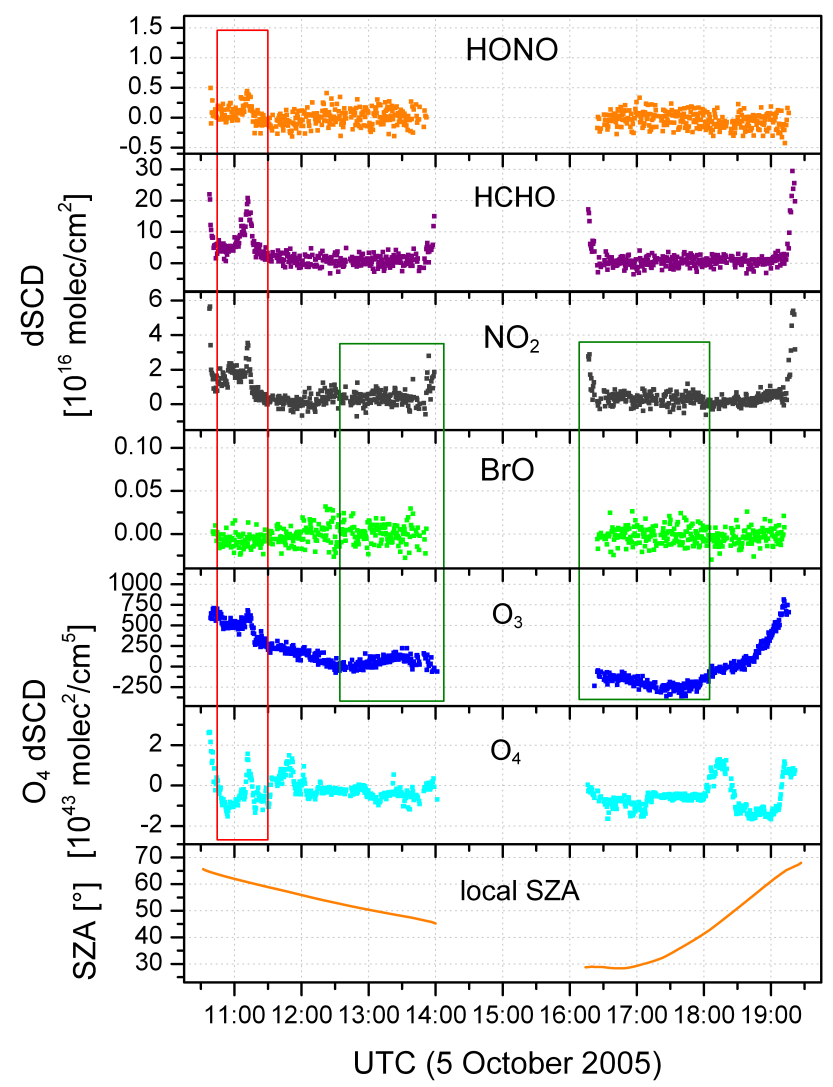

Fig. 9. DOAS results for a return flight from São Paulo to Santiago de Chile (left) and back (right). Biomass burning signatures are marked with a red box, while flying in stratospheric air is indicated by green boxes. The reference spectrum is recorded at 12:33 UTC.

A similar, but more pronounced event is shown in Fig. 10, were simultaneously enhanced $\mathrm{BrO}, \mathrm{NO}_{2}$ and $\mathrm{O}_{3}$ levels could be measured over the Tibetan Plateau by the $10^{\circ}$ downward viewing direction on 1 August 2006 (red box). Because of the above mentioned reduced light gain of this viewing angle, spectra were co-added to yield a time resolution of $2 \mathrm{~min}$ and $12 / 20$ min respectively to achieve a better signal-to-noise ratio. $\left(\mathrm{O}_{3}\right.$ slant column densities are derived from the $\mathrm{BrO}$ analysis, as the spectra quality did not permit an analysis at shorter wavelengths, where the $\mathrm{O}_{3}$ absorption is stronger.) Since the nadir viewing direction shows no elevated values for the respective trace gases during the same period and as both viewing directions are similarly sensitive to the stratosphere, it can be safely assumed that the measured trace gases are located beneath the aircraft in the troposphere, where the $10^{\circ}$ viewing direction exhibits its highest sensitivity. The origin of this air mass is very likely stratospheric: In Fig. 11 potential vorticity values for this flight over central Asia are plotted, indicating the course of the tropopause in yellow to red shading. A blue box encloses regions with elevated PV values in the troposphere $\left(84.4^{\circ}-105.2^{\circ} \mathrm{E}, 41.1^{\circ}-29.5^{\circ} \mathrm{N}\right.$, flight altitude $=11.4 \mathrm{~km}$ ), which are very probably remnants 


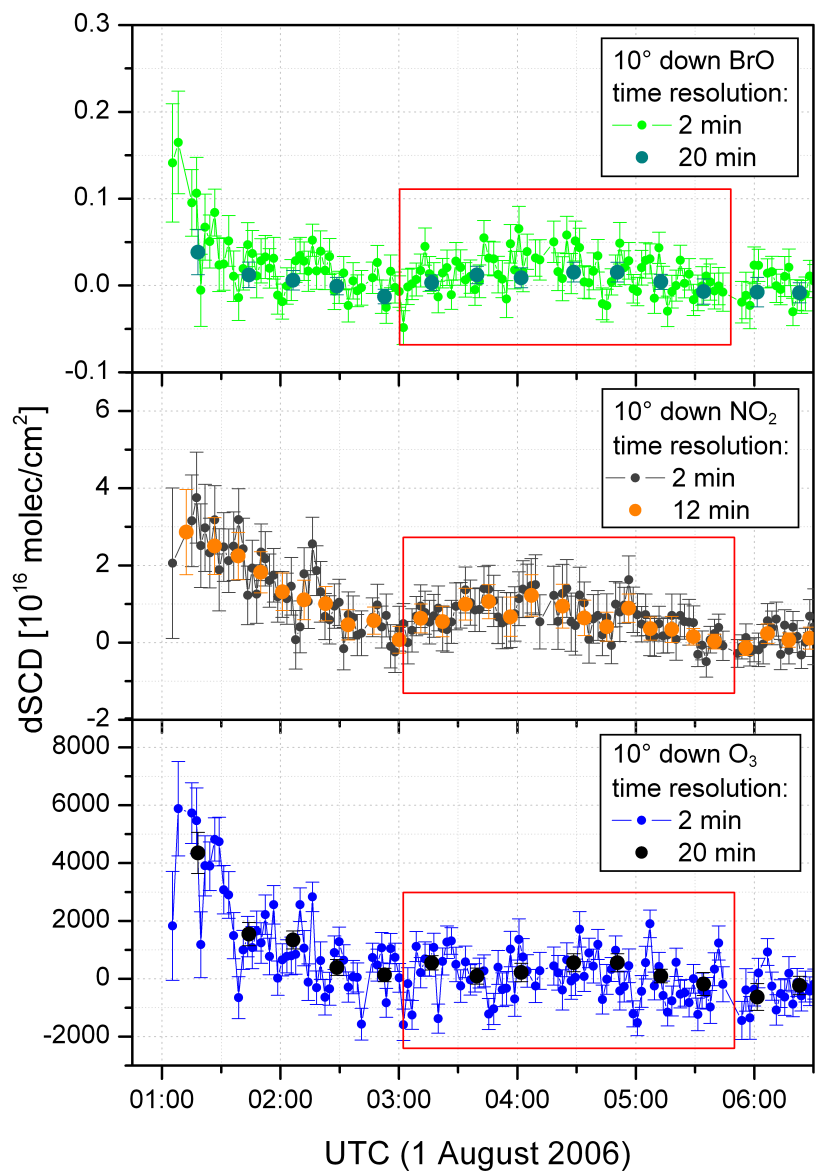

Fig. 10. $\mathrm{BrO}, \mathrm{NO}_{2}$ and $\mathrm{O}_{3} \mathrm{dSCD}$ of the $10^{\circ}$ down viewing direction for flight LH158 on 1 August 2006. The reference spectrum is recorded at 04:48 UTC with a SZA of $15.8^{\circ}$. Higher slant columns between 01:00 and 03:00 UTC are caused by a rising sun and corresponding light path enhancements in the stratosphere. The red boxes mark episodes of elevated tropospheric $\mathrm{BrO}, \mathrm{NO}_{2}$, and $\mathrm{O}_{3}$.

of a dissipated tropopause fold. Judging from camera and $\mathrm{O}_{4}$ data, a cloud free atmosphere was present below the aircraft between about 03:30-05:30 UTC. Assuming that 1) stratospheric contributions are canceled out by the reference spectrum taken at 04:48 UTC, and that 2) the observed trace gas columns are confined within the area of elevated PV values as shown in Fig. 11, i.e. between 8-11 km altitude, and homogeneously distributed, then averaged mixing ratios for this area $(\mathrm{AMF}=6.7$ ) yield about $6 \mathrm{ppt} \mathrm{BrO}, 0.5 \mathrm{ppb} \mathrm{NO} 2$ and $230 \mathrm{ppb}$ $\mathrm{O}_{3}$ for the slant column density maxima at 04:15 UTC. In light of the above discussed reduced spectra quality of the $10^{\circ}$ down viewing direction and the underlying assumption, an overall error of about $30 \%$ is estimated for these mixing ratios. The $\mathrm{NO}_{2}$ value might be biased by a tropospheric background. However, this might largely be excluded for $\mathrm{BrO}$ since typical tropospheric mixing ratios are in the order of 0.6-3 ppt (e.g. Fitzenberger et al., 2000; Hendrick et al., 2007; Theys et al., 2007). The observed mixing ratio of $6 \mathrm{ppt}$

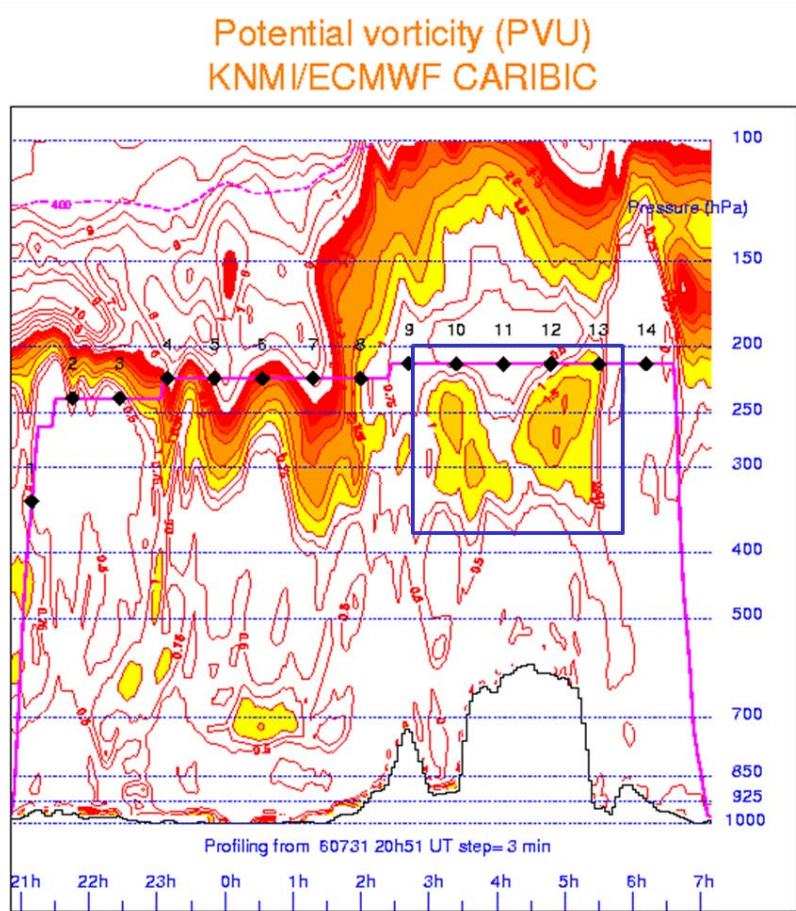

Fig. 11. PV values derived from ECMWF data for flight LH158 (provided by P. van Velthoven, KNMI, see http://www.knmi.nl/ samenw/campaign_support/CARIBIC). The PV plot shows the flight track over the Tibetan Plateau and potential vorticity (red contours) with values between 1 and 5 PVU shaded from yellow to red. The blue box indicates elevated PV values in the troposphere, probably caused by a dissolved tropopause fold.

$\mathrm{BrO}$ and particularly the high ozone mixing ratio support the assumption that this air mass originated in the stratosphere.

During ascent and descent of the aircraft, information on the local boundary layer is gained. To obtain this information, a boundary layer profile retrieval of $\mathrm{NO}_{2}$ was tried on data measured during a descent in Guangzhou, China on 1 August 2006. The retrieval was performed using the well known optimal estimation method (Rodgers, 2000), where a best estimate of the vertical profile is determined using the measured SCDs, an a priori profile, and the Box-AMFs as weighting functions. The inversion algorithm is implemented in McArtim (Deutschmann and Wagner, 2008; Wagner et al., 2007), the successor of Tracy II (see above). This program was also used for the respective AMF modelling. In order to derive suitable Box-AMFs, a cloud free descent was chosen and the aerosol profile was constrained by modelling different aerosol scenarios until measured and modelled $\mathrm{O}_{4}$ values agreed (for retrieving information of aerosol properties by $\mathrm{O}_{4}$ measurements see e.g. Wagner et al., 2004; Wittrock et al., 2004; Sinreich et al., 2005; Frieß et al., 2006). Therefore aerosol optical density, profile height and single scattering albedo were varied, while the asymmetry parameter $g$ was fixed to 0.68 , representing urban aerosol. The best 


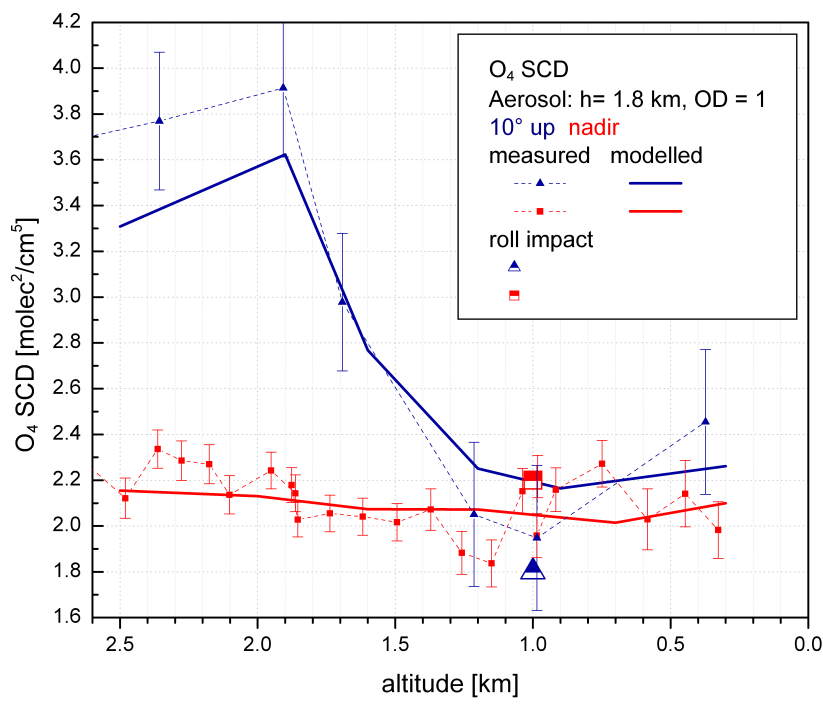

Fig. 12. Measured and modelled $\mathrm{O}_{4} \mathrm{SCDs}$ in order to derive information on the aerosol profile upon descent in Guangzhou, China on 1 August 2006. The retrieved aerosol profile served as input parameter for a $\mathrm{NO}_{2}$ profile retrieval. Data points labeled as "roll impact" mark the effect of an aircraft turn within the aerosol layer with a maximum roll angle of $15^{\circ}$. This change in roll angle affects directly the telescope viewing directions and is correlated with the deviation of the measured $\mathrm{O}_{4}$ columns at this altitude $(h=1 \mathrm{~km})$.

match of measured and modelled $\mathrm{O}_{4}$ values is achieved for an aerosol box profile with an optical density of 1 , a height of $1.8 \mathrm{~km}$ and a single scattering albedo of 0.75 . Results for the $10^{\circ}$ up and nadir viewing directions are shown in Fig. 12. The strong reduction of $\mathrm{O}_{4}$ columns seen in the $10^{\circ}$ up viewing direction upon entering the aerosol layer indicates highly absorbing aerosol. (The $10^{\circ}$ down viewing direction was omitted, due to rather large uncertainties in the retrieval of the $\mathrm{O}_{4}$ column contained in the reference spectrum).

$\mathrm{NO}_{2}$ columns from all viewing directions served as input parameters for the trace gas profile retrieval, with nadir SCDs contributing with a $30 \mathrm{~s}$ time resolution (corresponding to a 100-200 m height resolution), and both up and down viewing directions $\left( \pm 10^{\circ}\right)$ with a 2 min time resolution (corresponding to a $400-800 \mathrm{~m}$ height resolution).

The boundary layer is about $2 \mathrm{~km}$ high at 14:00 local time and can be assumed to be well mixed. The retrieved profile in Fig. 13 shows a distinct shape, different from the a priori, and also exhibits smaller errors, which is an indication that most of the profile information is taken from the measurements. Accordingly, profile inversion from CARIBIC DOAS measurements seems to be a suitable concept. However, the facts that the aircraft maneuvered within the boundary layer, that the nadir data contains little vertical information and that data of the slant directions are of inferior quality, limit the spatial information content of these measurements. The total descent inside this boundary layer averaged over a $50 \mathrm{~km}$ dis-

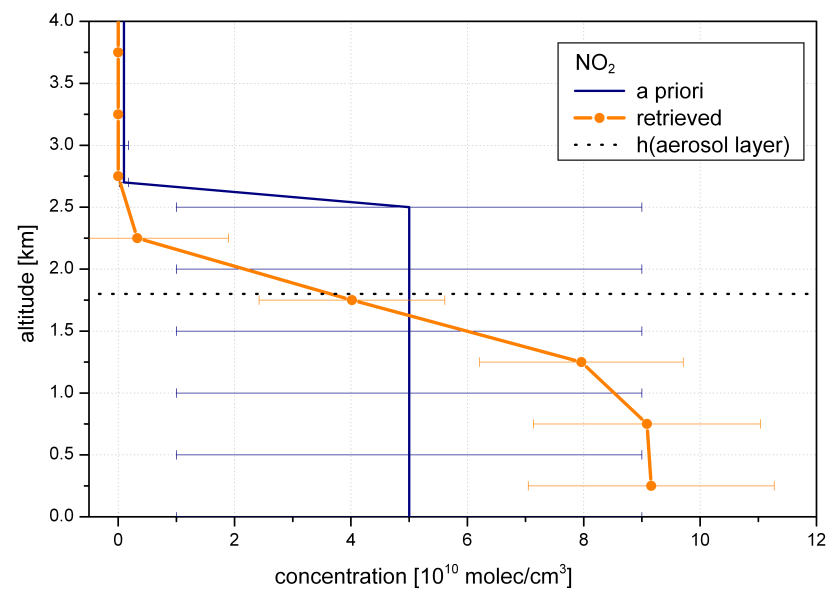

Fig. 13. $\mathrm{NO}_{2}$ profile retrieved by optimal estimation method with a height resolution of $500 \mathrm{~m}$. Data is taken from a descent in Guangzhou, China on 1 August 2006. The dashed line indicates the height of the aerosol box profile used in the retrieval.

tance to the airport. Therefore the retrieved aerosol profile as well as the retrieved concentrations are the product of averaging over locally varying aerosol and trace gas distributions. Sensitivity studies need to be conducted to provide further insight on the accuracy of this profile retrieval. The derived mixing ratio from this retrieval calculates to $4.1 \mathrm{ppb} \pm 0.9 \mathrm{ppb}$ $\mathrm{NO}_{2}$ for $0-1 \mathrm{~km}$ altitude.

\section{Conclusions and outlook}

Most parts of the CARIBIC DOAS instrument performed reliably during 30 flight operations. Three years of continuous exposure of the telescope block inside the pylon to the almost daily harsh conditions of pressure changes, temperature variations, and changes from extreme tropical humidity to dry stratospheric air have been an ultimate test for the system: The connections between the quartz fibre bundles and the telescope block have shown to be critical and the spectral filters are fragile. On the other hand, the quartz fibre bundles appear to be rather robust, even though they remain a critical part in this system. With respect to the overall flight performance, the following conclusions can be drawn:

- DOAS spectra could be recorded on each daytime flight.

- After software improvements, the DOAS instrument provides reliable and fully automated measurements of scattered light spectra during day and background spectra during night.

- The $30 \mathrm{~s}$ time resolution is suitable for the analysis of most trace gases in the nadir viewing direction. It allows the resolution of unique events as shown by the detection of HONO in a deep convective cloud and will 
very likely also be suitable for the analysis of the other viewing directions in the future.

- With all three viewing directions operational - since February 2008, the CARIBIC DOAS has gained back its full spatial resolution, which will make measurements much more sensitive to trace gases in the free troposphere. On average the spatial resolution is $7-8 \mathrm{~km}$ along flight track (determined by aircraft velocity), with the highest sensitivities directly above and below the aircraft.

This novel instrumentation provides a multitude of interesting observations and can contribute to different scientific topics:

- CARIBIC DOAS measurements are well suited for tropospheric plume studies. Especially with the up and down viewing directions working again, the sensitivity to the troposphere and UTLS region is increased, and separation of stratospheric and tropospheric columns can be performed more precisely, which yields an improved quantification of tropospheric absorbers.

- CARIBIC DOAS measurements contain information on stratospheric trace gases and can possibly add insight to the question on the contribution of tropopause folds to troposphere- stratosphere exchange.

- Upon ascent and descent of the aircraft, vertical information on the boundary layer is gained, yielding information on local pollution and with the potential for boundary layer profile retrievals.

A great potential of these measurements is that any single flight offers the possibility of unexpected findings. Continued work with the CARIBIC DOAS system will be based on making use of the newly gained spatial information and sensitivity by all viewing directions. Further studies will include a complete use of all current CARIBIC data, which can yield information on origin, age, and chemistry of different air masses, on sources and sinks of trace gases as well as on aerosol (optical) properties. A more light efficient spectrograph-detector unit would improve current detection limits and could enable the detection of IO, glyoxal and water vapour. Such units that would still comply with weight and power requirements are by now commercially available (e.g. Ocean Optics QE65000). Since the total CARIBIC project time is at least 10 years, statistical analysis of the dataset can provide valuable information on trends and anomalies in trace gas distributions.
Acknowledgements. We thank the CARIBIC team, particularly Dieter Scharffe, Franz Slemr, Claus Koeppel, Markus Hermann and Andreas Zahn.

Thank you to Tim Deutschmann for providing TRACY-2 and McArtim and thanks to Lufthansa and Lufthansa Technik for the ongoing good cooperation.

Edited by: M. Weber

\section{References}

Acker, K., Möller, D., Wieprecht, W., Meixner, F., Bohn, B., Gilge, S., Plass-Dülmer, C., and Berresheim, H.: Strong daytime production of $\mathrm{OH}$ from $\mathrm{HNO}_{2}$ at a rural mountain site, Geophys. Res. Lett., 33, L02809, doi:10.1029/2005GL024643, 2006.

Bogumil, K., Orphal, J., Homann, T., Voigt, S., Spietz, P., Fleischmann, O. C., Vogel, A., Hartmann, M., Bovensmann, H., Frerick, J., and Burrows J. P.: Measurements of molecular absorption spectra with the SCIAMACHY pre-flight model: Instrument characterization and reference data for atmospheric remotesensing in the 230-2380 $\mathrm{nm}$ region, J. Photoch. Photobio. A, 157, 167-184, 2003.

Brenninkmeijer, C. A. M., Crutzen, P., Boumard, F., Dauer, T., Dix, B., Ebinghaus, R., Filippi, D., Fischer, H., Franke, H., Frie?, U., Heintzenberg, J., Helleis, F., Hermann, M., Kock, H. H., Koeppel, C., Lelieveld, J., Leuenberger, M., Martinsson, B. G., Miemczyk, S., Moret, H. P., Nguyen, H. N., Nyfeler, P., Oram, D., O’Sullivan, D., Penkett, S., Platt, U., Pupek, M., Ramonet, M., Randa, B., Reichelt, M., Rhee, T. S., Rohwer, J., Rosenfeld, K., Scharffe, D., Schlager, H., Schumann, U., Slemr, F., Sprung, D., Stock, P., Thaler, R., Valentino, F., van Velthoven, P., Waibel, A., Wandel, A., Waschitschek, K., Wiedensohler, A., Xueref-Remy, I., Zahn, A., Zech, U., and Ziereis, H.: Civil Aircraft for the regular investigation of the atmosphere based on an instrumented container: The new CARIBIC system, Atmos. Chem. Phys., 7, 4953-4976, 2007,

http://www.atmos-chem-phys.net/7/4953/2007/.

Bhetanabhotla, M. N., Crowell, B. A., Coucouvinos, A., Hill, R. D., and Rinker, R. G.: Simulation of trace species production by lightning and corona discharge in moist air, Atmos. Environ., 19, 1391-1397, 1985.

Bruns, M., Buehler, S. A., Burrows, J. P., Heue, K.-P., Platt, U., Pundt, I., Richter, A., Rozanov, A., Wagner, T., and Wang, P.: Retrieval of Profile Information from Airborne Multi Axis UV/visible Skylight Absorption Measurements, Appl. Optics, 43(22), 4415-4426, 2004.

Bruns, M., Buehler, S. A., Burrows, J. P., Richter, A., Rozanov, A., Wang, P., Heue, K. P., Platt, U., Pundt, I., and Wagner, T.: $\mathrm{NO}_{2}$ Profile retrieval using airborne multi axis UV-visible skylight absorption measurements over central Europe, Atmos. Chem. Phys., 6, 3049-3058, 2006,

http://www.atmos-chem-phys.net/6/3049/2006/.

Deutschmann, T. and Wagner, T.: TracyII and McArtim Documentation, http://joseba.mpch-mainz.mpg.de/matr/tracy_II, 2007.

Fayt, C. and van Roozendael, M.: WinDOAS 2.1. Software User Manual, 2001.

Fitzenberger, R., Bösch, H., Camy-Peyret, C., Chipperfield, M., Harder, H., Platt, U., Sinnhuber, B.-M., Wagner, T., and Pfeil- 
sticker, K.: First profile measurement of tropospheric BrO, Geophys. Res. Lett., 27, 2921-2924, 2000.

Frieß, U., Monks, P. S., Remedios, J. J., Rozanov, A., Sinreich, R., Wagner, T., and Platt, U.: MAX-DOAS $\mathrm{O}_{4}$ measurements: A new technique to derive information on atmospheric aerosols: 2. Modelling studies, J. Geophys. Res., 111, D14203, doi:10.1029/2005JD006618, 2006.

Hendrick, F., van Roozendael, M., Chipperfield, M. P., Dorf, M., Goutail, F., Yang, X., Fayt, C., Hermans, C., Pfeilsticker, K., Pommereau, J.-P., Pyle, J. A., Theys, N., and Maziere, M. D.: Retrieval of stratospheric and tropospheric $\mathrm{BrO}$ profiles and columns using ground-based zenith-sky DOAS observations at Harestua, $60^{\circ} \mathrm{N}$, Atmos. Chem. Phys., 7, 4869-4885, 2007, http://www.atmos-chem-phys.net/7/4869/2007/.

Hermans, C.: Personal communication, http://www.aeronomie.be/ spectrolab/o2.htm, 2002.

Heue K.-P., Bruns, M., Burrows, J. P., von Friedeburg, C., Lee, W.-D., Platt, U., Pundt, I., Richter, A., Wagner, T., and Wang, P.: Validation of scientific $\mathrm{NO}_{2}$-SCIAMACHY data using the AMAXDOAS instrument, Atmos. Chem. Phys., 5, 1039-1051, 2005

http://www.atmos-chem-phys.net/5/1039/2005/.

von Glasow, R., von Kuhlmann, R., Lawrence, M. G., Platt, U., and Crutzen, P. J.: Impact of reactive bromine chemistry in the troposphere, Atmos. Chem. Phys., 4, 2481-2497, 2004, http://www.atmos-chem-phys.net/4/2481/2004/.

Grainger, J. F. and Ring, J.: Anomalous Fraunhofer line profiles, Nature, 193, p. 762, 1962.

Kleffmann, J., Becker, K., and Wiesen, P.: Heterogeneous $\mathrm{NO}_{2}$ conversion processes on acid surfaces: possible atmospheric implications, Atmos. Environ., 32, 2721-2729, 1998.

Kraus, S.: DOASIS, A Framework Design for DOAS, Ph.D. thesis, University of Heidelberg, Germany, 2006.

Lammel, G. and Cape, J. N.: Nitrous Acid and Nitrite in the Atmosphere, Chem. Soc. Rev., 25, 361-369, 1996.

Marquard, L., Wagner, T., and Platt, U.: Improved air mass factor concepts for scattered radiation Differential Optical Absorption Spectroscopy of atmospheric Species, J. Geophys. Res., 105, 1315-1327, 2000.

Meller, R. and Moortgat, G. K.: Temperature dependence of the absorption cross sections of $\mathrm{HCHO}$ between 223 and $323 \mathrm{~K}$ in the wavelength range $225-375 \mathrm{~nm}$, J. Geophys. Res., 105, 7089$7102,2000$.

Perliski, L. M. and Solomon, S.: On the evaluation of air mass factors for atmospheric near-ultraviolet and visible absorption spectroscopy, J. Geophys. Res., 98, 10363-10374, 1993.

Platt, U. and Perner, D.: Direct Measurements of Atmospheric $\mathrm{CH}_{2} \mathrm{O}, \mathrm{HNO}_{2}, \mathrm{O}_{3}, \mathrm{NO}_{2}$ and $\mathrm{SO}_{2}$ by Differential Optical Absorption in the Near UV, J. Geophys. Res., 85, 7453-7458, 1980.

Platt, U.: Differential Optical Absorption Spectroscopy (DOAS), in: Monitoring by Spectroscopic Techniques, edited by: Sigrist, M. W., New York: John Wiley \& Sons, Inc., 1994.

Platt, U. and Stutz, J.: Differential Optical Absorption Spectroscopy, Principles and Applications, Springer-Verlag, Germany, 2008.

Rodgers, C. D.: Inverse Methods for Atmospheric Sounding, Worlds Scientific, London, UK, 2000.

Saiz-Lopez, A., Shillito, J. A., Coe, H., and Plane, J. M. C.: Measurements and modelling of $\mathrm{I}_{2}, \mathrm{IO}, \mathrm{OIO}, \mathrm{BrO}$ and $\mathrm{NO}_{3}$ in the mid-latitude marine boundary layer, Atmos. Chem. Phys., 6, 1513-1528, 2006,

http://www.atmos-chem-phys.net/6/1513/2006/.

Simpson, W. R., von Glasgow, R., Riedel, K., Anderson, P., Ariya, P., Bottenheim, J., Burrows, J., Carpenter, L., Frieß, U., Goodsite, M., Heard, D., Hutterli, M., Jacobi, H.-W., Kaleschke, H., Neff, W., Plane, J., Platt, U., Richter, A., Roscoe, H., Sander, R., Shepson, P., Sodeau, J., Steffen, A., Wagner, T., and Wolff, E.: Halogens and their role in polar boundary-layer ozone depletion, Atmos. Chem. Phys. 7, 4375-4418, 2007.

Sinreich, R., Frieß, U., Wagner, T., and Platt, U.: Multi Axis Differential Optical Absorption Spectroscopy (MAX-DOAS) of gas and aerosol distributions, Faraday Discuss., 130, 153-164, 2005.

Solomon, S., Schmeltekopf, A. L., and Sanders, R. W.: On the interpretation of zenith sky absorption measurements, J. Geophys. Res., 92, 8311-8319, 1987.

Stutz, J. and Platt, U.: Numerical Analysis and Estimation of the Statistical Error of Differential Optical Absorption Spectroscopy Measurements with Least-Squares methods, Appl. Optics., 35, 6041-6053, 1996.

Stutz, J. and Platt, U.: Improving longpath differential optical absorption spectroscopy with a quartz-fibre mode mixer, Appl. Optics., 36, 1105-1115, 1997.

Stutz, J., Kim, E., Platt, U., Bruno, P., Perrino, C., and Febo, A.: UV-visible absorption cross section of nitrous acid, J. Geophys. Res., 105, 14858-14592, 2000.

Theys, N., Van Roozendael, M., Hendrick, F., Fayt, C., Hermans, C., Baray, J.-L., Goutail, F., Pommereau, J.-P., and De Mazière, M.: Retrieval of stratospheric and tropospheric $\mathrm{BrO}$ columns from multi-axis DOAS measurements at Reunion Island $\left(21^{\circ} \mathrm{S}\right.$, $56^{\circ}$ E), Atmos. Chem. Phys, 7, 4733-4749, 2007.

Vandaele, A. C., Hermans, C., Simon, P. C., Carleer, M., Colin, R., Fally, S., Merienne, M.-F., Jenouvrier, A., and Coquart, B.: Measurements of the $\mathrm{NO}_{2}$ absorption cross-section from $42000 \mathrm{~cm}^{-1}$ to $10000 \mathrm{~cm}^{-1}$ (238 to $\left.1000 \mathrm{~nm}\right)$ at $220 \mathrm{~K}$ and 294 K, J. Quant. Spectrosc. Radiat. Transfer, 59, 171-184, 1997.

Volkamer, R., Sheehy, P. M., Molina, L. T., and Molina, M. J.: Oxidative capacity of the Mexico City atmosphere Part 1: A radical source perspective, Atmos. Chem. Phys. Discuss., 7, 5365-5412, 2007 , http://www.atmos-chem-phys-discuss.net/7/5365/2007/.

Wagner, T., Dix, B., von Friedeburg, C., Frieß, U., Sanghavi, S., Sinreich, R., and Platt, U.: MAX-DOAS $\mathrm{O}_{4}$ measurements: A new technique to derive information on atmospheric aerosols. Principles and information content, J. Geophys. Res. 109, D22205, doi:10.1029/2004JD004904, 2004.

Wagner, T., Burrows, J. P., Deutschmann, T., Dix, B., von Friedeburg, C., Frieß, U., Hendrick, F., Heue, K.-P., Irie, H., Iwabuchi, H., Kanaya, Y., Keller, J., McLinden, C. A., Oetjen, H., Palazzi, E., Petritoli, A., Platt, U., Postylyakov, O., Pukite, J., Richter, A., van Roozendael, M., Rozanov, A., Rozanov, V., Sinreich, R., Sanghavi, S., and Wittrock, F.: Comparison of box-airmass-factors and radiances for Multiple-Axis Differential Optical Absorption Spectroscopy (MAX-DOAS) geometries calculated from different UV/visible radiative transfer models, Atmos. Chem. Phys., 7, 1809-1833, 2007, http://www.atmos-chem-phys.net/7/1809/2007/.

Wahner, A., Callies, J., Dorn, H.-P., Platt, U., and Schiller, C.: Near UV Atmospheric Absorption Measurements of Column Abun- 
dances During Airborne Arctic Stratospheric Expedition, Jan.Feb. 1989: 1. Technique and $\mathrm{NO}_{2}$ Observations, Geophys. Res. Lett., 17, 497-500, 1990.

Wang, P., Richter, A., Bruns, M., Rozanov, V. V., Burrows, J. P., Heue, K.-P., Wagner, T., Pundt, I., and Platt, U.: Measurements of tropospheric $\mathrm{NO}_{2}$ with an airborne multi-axis DOAS instrument, Atmos. Chem. Phys., 5, 337-343, 2005, http://www.atmos-chem-phys.net/5/337/2005/.

Wang, P., Richter, A., Bruns, M., Burrows, J. P., Scheele, R., Junkermann, W., Heue, K.-P., Wagner, T., Platt, U., and Pundt, I.: Airborne multi-axis DOAS measurements of tropospheric $\mathrm{SO}_{2}$ plumes in the Po-valley, Italy, Atmos. Chem. Phys., 6, 329-338, 2006,

http://www.atmos-chem-phys.net/6/329/2006/.
Wilmouth, D. M., Hanisco, T. F., Donahue, N. M., and Anderson, J. G.: Fourier transform ultraviolet spectroscopy of the $\mathrm{A}^{2} \Pi_{3 / 2}^{\leftarrow} \mathrm{X}^{2} \Pi_{3 / 2}$ transition of BrO, J. Phys. Chem., 103, 8935$8945,1999$.

Wittrock, F., Oetjen, H., Richter, A., Fietkau, S., Medeke, T., Rozanov, A., and Burrows, J. P.: MAX-DOAS measurements of atmospheric trace gases in Ny-Alesund - Radiative transfer studies and their application, Atmos. Chem. Phys., 4, 955-966, 2004, http://www.atmos-chem-phys.net/4/955/2004/. 